\title{
PERCEPTIONS OF SOCIAL NETWORK USABILITY: IMPACTS OF PERCEIVED INTERACTIVITY AND TECHNOLOGY ACCEPTANCE
}

\author{
Belinda Shipps, North Carolina A \& T State University, bpshipps@ ncat.edu \\ Brandis Phillips, North Carolina A \& T State University, bphillip@ ncat.edu
}

\begin{abstract}
The technology acceptance model (TAM) has been tested within a variety technological contexts. This research aims to extend TAM in a social networking context. As Web 2.0 tools become more prevalent, it becomes more important to examine how and why users are accepting these new technologies. Thus, we develop and test a conceptual model based in part on TAM as well as on literature from the marketing area to gain an understanding of why individuals consider using Web 2.0 tools. Results suggest that the usability of a Web 2.0 tool is significantly impacted by perceptions of the degree of interactivity it enables, as well as by the perceived usefulness of the website as mediated through perceived attitudes toward the Web 2.0 tool.
\end{abstract}

Keywords: Social networks, information systems, technology acceptance, perceived interactivity, usability

\section{INTRODUCTION}

Over the last few years, Web 2.0 tools have exploded in their usage among Internet users. The popular press has documented this unprecedented growth, noting that overall usage for the Facebook social networking site alone has more than doubled from 2008 levels to 175 million users in February 2009 [14]. Other sites such as Bebo, Myspace, and Linkedin have also seen large increases in member enrollment. Growth in such sites can be attributed to increases in wireless users [11] and claims of increases in worker productivity [15], and the usage of social networking tools has surpassed e-mail use in popularity [7]. Furthermore, anecdotal evidence during and after the recent presidential election, during which President Obama consistently used Myspace, Facebook, and Youtube, demonstrates that social networking is quickly gaining a large following. Other examples include media outlets such as CNN using Facebook and Twitter to disseminate news directed to specific audiences.

With most technologies, demographic penetration is usually limited to certain segments of the population. Specific audiences are usually targeted, and penetration of a technology is therefore limited to some degree [31] [32]. For example, technologies that are used for special needs such as blind, deaf, or autistic users may be targeted to specific audiences [31] [32]. Social networking websites, however, have broken the mold in regard to demographic penetration. Recent demographic data from Facebook (as of 1/4/10) indicates that the number of new U.S.based users has grown by over $100 \%$ in the past 14 months, while all age groups have grown by at least $50 \%$. Furthermore, the 35- to 54-year-old category has grown more than any other category, seeing a tenfold increase during the same 14-month time period [5]. What's more, as of 1/4/2010, overall growth has increased by 100\% from 2009 levels, while the 55-plus age group has increased by over $900 \%$ [6].

There are many reasons for this aggressive growth in the use of Web 2.0 tools, including entertainment value, connecting or reconnecting with friends, and socializing with new and existing friends and colleagues. Individual reasons and characteristics for joining a social networking site are similar to basic network effects [16]. As more people join a network, its website garners more value for the individual members. The more that people who know one another are on the website, the more likely they are to engage in online activity within the site for purposes of socializing. Furthermore, with an increased ability to personalize individual websites, there is a greater likelihood of a higher degree of ownership. Thus, the growth in social networking websites is subject to the same economic principles as other networks.

Given the exponential growth in the popularity of these Web 2.0 tools, our aim is to extend the technology acceptance model (TAM) to better understand why individuals accept Web 2.0 tools. Therefore, we propose to provide a conceptual model depicting the relationship between perceptions of website usability (in a social networking context) and the antecedents to such usability revolving around technology acceptance. This paper is organized as follows: section 2 provides a literature review as the theoretical basis for our inquiry; section 3 introduces the model and constructs; section 4 introduces the model and hypothese; and section 5 presents a 
discussion of the proposed study followed by the conclusion.

\section{LITERATURE REVIEW}

Behavior and intent to engage in a social relationship online is different from traditional face-to-face networking. Online behavior involves a more integrated approach that focuses on interaction with information, people, and technology. Many factors may lead to an individual visiting a social networking website. We suggest that an individual's behavior or intent to find a social networking site that they feel is usable may be related to perceptions associated with both technological- and emotional-based factors. The following literature review provides support for the conceptual model and will give an overview of the previous literature revolving around technology acceptance and interaction among individuals.

Theory of Reasoned Action (TRA)-TRA provides support in explaining the social-psychological factors that may influence perceived interactivity and the use of a social networking website in terms of actual behavior and behavioral intentions. TRA is based on research and principles inherent in social psychology [9] which help make sense of and predict individual behavior in social settings. Ajzen [3] states that individual beliefs affect actual behavior or behavioral perceptions [9] Furthermore, TRA suggests that actual behavior relates to an individual's behavioral intentions (BIs). Behavioral intentions are influenced by: (a) individual attitude regarding the behavior; and (b) social norms, which are defined as individual perceptions of social demands or pressures. TRA has been used to help understand shopping behavior [28], consumer complaints and purchasing behavior [19, $21]$, and information systems [8, 13, 24, 26, 27].

\section{Technology Acceptance Model (TAM)-The} technology acceptance model (TAM), based in part on the theory of reasoned action, provides support in explaining the technological factors that may affect the use of a social networking website. TAM was developed [8] to help explain why people accept or reject computer technology. TAM is based upon the argument that the individual impact of perceived usefulness and ease of use of technology will influence the attitude of an individual when using a particular technology, and will also have an impact on their behavioral intent to use computer technology.
Perceived Interactivity Theory (PI) - A key part of social networking involves interaction among different individuals in an online social setting. Social networking sites allow interaction or communication in a one-to-one or one-to-many online scenario using different website features. Usage may affect perceptions associated with the interaction with website features relating to communication and quality of the message. According to telepresence theory [23] and interactivity theory [20], the message and the mediated environment are associated with perceptions of interactivity. Telepresence theory suggests that an individual's relationship to a communication medium and its characteristics influences perceived interactivity [23]. Interactivity theory posits that the quality of the communication has a positive effect on perceived interactivity [20]. Interactivity can play an essential role in web-based, network-oriented environments [22]. Findings in the literature focus on two dimensions of perceived interactivity: (1) the individual's sense of efficacy; and (2) the individual's sense of the media system's interactivity [18], including an emphasis on the "direction of communication" $[12,20]$.

\section{Constructs}

Technology Acceptance-A large body of the information systems literature has revolved around technology usage and acceptance. For purposes of this study, two factors from the technology acceptance model-perceived usefulness and perceived ease of use - will be incorporated into the research model. Perceived usefulness is defined as "the prospective user's subjective probability that using a specific application system will increase his or her job performance within an organizational context" [8]. In relation to social networking, the application in question can be associated with the social networking website itself, and the context is the individual's personal view of usefulness. Perceived ease of use is defined as "the degree to which the prospective user expects the target system to be free of effort" [8]. In a social networking setting on the Web, ease of use is paramount to encourage individuals to spend time on the site and easily connect with others. This perception may be influenced by their attitudes toward social networks. Attitude is defined as "the degree to which a person has a favorable or unfavorable evaluation or appraisal of the behavior in question" [2]. Previous research demonstrates an association between attitude and perceptions about technology [8]. In regard to social networking, an individual's attitude toward social 
networks may affect their perceptions regarding its usefulness and perceived ease of use.

Perceived Interactivity-The degree to which an individual interrelates with a website is measured through an individual's perceived belief regarding the website's interactivity. Perceived interactivity is a combination of communication, control, and responsiveness [22]. Where 'communication' refers to two-way communication via the website, 'control' refers to the degree to which the individual user is in command of their web experience while on the site. Finally, 'responsiveness' refers to the website's technical ability to respond in a timely manner to user input.

Usability - The degree of usability in software and websites is a key indicator of how much users will continue to use the software or website. Usability for the Web specifically has been viewed as a key metric for evaluating the success or failure of an organizations' website [1]. With regard to this study, usability is operationalized as an overall measure of an individual's perceptions of how a Web 2.0 tool satisfies their user experience. This operationalization is more general than the TAM-related constructs (perceived usefulness and perceived ease of use), since they ask targeted questions revolving around ease of use and usefulness.

Control Variables-Since it is plausible that individual differences might have some affect on the usage of Web 2.0 tools, factors such as age, gender, education, income, and ethnicity are plausible choices to be included in the research model.

\section{RESEARCH MODEL}

The research model depicted in figure 1 below will attempt to explain variance in website usage in a social networking context. The model is specifically put forth to answer the following research question:

What factors significantly impact website usability in a social networking context?

--- insert figure 1 here ----

The following will present the Hypotheses related to the research model.

\section{Perceived ease of use and perceived usefulness}

Consistent with prior technology acceptance literature, the perceived ease of use of a technology should lead to perceptions of its usefulness for users. In a Web 2.0 context, we hypothesize that the same should be true. If a Web 2.0 tool is perceived to be simple to use for the tasks a user would most likely perform, then the usefulness of the Web 2.0 tool should increase for the user. Therefore the following hypothesis is put forth:

Hypothesis 1: Increases in perceptions of ease of use in a Web 2.0 tool should lead to increased perceptions of usefulness in a Web 2.0 tool.

\section{Perceived ease of use and attitude}

Consistent with the technology acceptance literature, the perceived ease of use of a technology should lead to a more positive attitude toward that technology. Within a Web 2.0 tool context, the easier an individual finds a particular technology, the more positive the individual should feel toward that technology. Therefore the following hypothesis is put forth:

Hypothesis 2: Increases in perceptions of ease of use in a Web 2.0 tool should lead to more positive attitudes in a Web 2.0 tool.

\section{Perceived usefulness and attitude}

Previous researchers have studied attitude and technology from different perspectives such as trust [17] and usefulness [27, [28]. According to previous TAM-related research, attitudes or beliefs about usefulness can impact website use [25]. Ajzen [3] argues that individual beliefs impact behavioral perceptions toward usefulness and perceived ease of use. Beliefs about technology in terms of perceptions of usefulness have also been shown to influence attitude [30, 21, 23, 9]. Therefore, consistent with prior literature, an individual's perceived usefulness of a technology should impact the individual's attitude regarding a social networking site. Thus the following hypothesis is put forth:

Hypothesis 3: Higher levels of perceived usefulness of a Web 2.0 tool will lead to a more positive attitude toward a Web 2.0 tool.

\section{Attitude and usability}

Attitude can impact how an individual feels about the usability of a social networking site. Previous research provides evidence for the importance of attitudes in the perception of usability, which can encourage continuous use [8].

Attitude will influence how a user feels about social network usability. Previous research on usability consistently supports the importance of attitude regarding technology use $[10,9,26,8]$. When social 


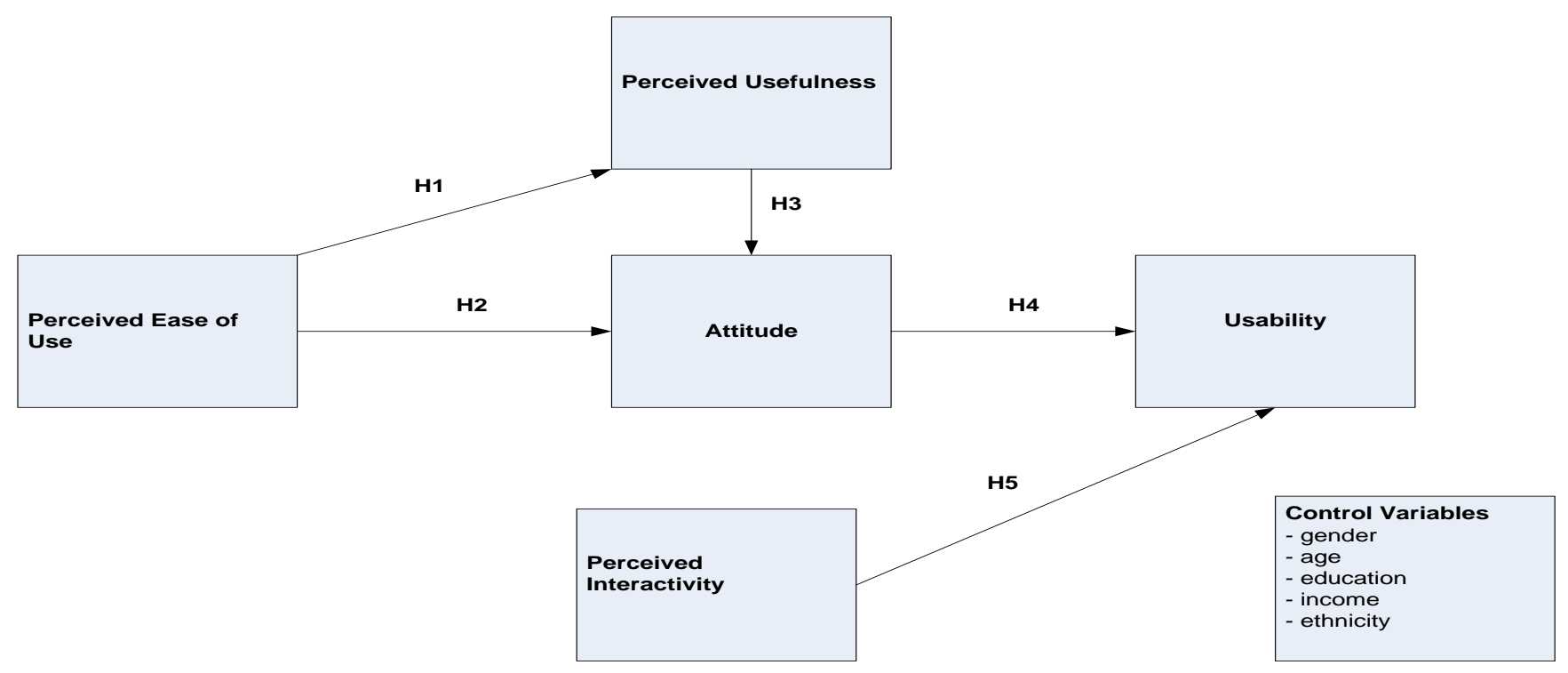

Figure 1. Research Model

network users feel their interaction with the site is useful in terms of communication, knowledge sharing, and establishing or renewing contacts, then they will perceive the site as useful. This, in turn, will encourage them to continue to return to the social networking site. When social network users feel their interaction with the site is clear and understandable without requiring a high level of effort, they will perceive the site as being easy to use, which will encourage them to continue to return to the social networking site. Thus the following hypothesis is put forth:

Hypothesis 4: Positive attitudes will have a positive effect on the perceptions of usability of a Web 2.0 tool.

\section{Perceived interactivity and usability}

The perceived interactivity of a website should have some impact upon what an individual perceives to be a usable website. Given the dimensions of perceived interactivity, when one feels in control of their experience - and also feels that the navigation of the website is very responsive to their needs - then there should be some feeling that there is a high degree of usability. Thus the following hypothesis is put forth:

Hypothesis 5: A higher degree of perceived interactivity of a social networking website will have a positive impact on the usability of a social networking website.

\section{METHOD}

A pilot study was conducted with students at a midsized southeastern U.S. university. Potential respondents were solicited from five different undergraduate management information systems and accounting classes. The total potential survey population was 130 students. The survey was administered on the Internet using Survey Monkey as the hosting tool. All survey items were measured using seven-point likert scales. Survey items included TAM-related variables, as well as those related to perceived interactivity, usability, and demographics. Potential respondents were also asked to answer the questions with regard to the social networking site they used the most. Finally, potential respondents were given a list of social networking sites and were instructed to choose the site they used most.

\section{Sample characteristics}

A total of 84 student respondents provided complete and usable surveys. Therefore the response rate was $65 \%$ (note the total number of surveys submitted was 90 , with 5 responses mostly incomplete and unusable). Sample characteristics were as follows. There were 47 male respondents $(56 \%)$ versus 37 female respondents (44\%). $96 \%$ of the respondents were in the 18 to 24 age category. 78 (or 93\%) of the respondents were African American. With regard to which social networking sites they used the most, the majority of the respondents (approximately 95\%) 
used Facebook, with the remaining respondents choosing Twitter.

\section{RESULTS}

\section{Measurement model}

Due to the modest nature of the sample size, partial least squares (PLS) was used to evaluate the model. PLS assesses reliability and validity by calculating the internal composite reliability (ICR) and the average variance extracted (AVE). The ICR is interpreted in the same manner as Cronbach's Alpha. An ICR of 0.7 is an indicator of sufficient reliability ${ }^{[10]}$. ICRs (reported in table 1) indicate sufficient reliability for all constructs (lowest $=0.76$ ). The AVE measures variance, as explained relative to measurement error. A valid construct has an AVE of greater than 0.50 [4], which indicates that the construct items consistently measure what is intended. Results in table 1 show that all of the constructs have AVEs of greater than 0.50, which is evidence of convergent validity.

Discriminant validity requires that constructs be distinct from one another. The test for discriminant reliability requires that the square roots of the AVEs for two latent variables must each be greater than the correlations between those two variables ${ }^{[10]}$. An examination of the correlations among the constructs in table 1 shows that the data pass this requirement, demonstrating adequate discriminant validity.

\section{Structural model}

The PLS structural model is interpreted like regression results. The path coefficients represent standard betas, while the $\mathrm{R}^{2}$ amount shown represents the variance explained. Given the research model, the following are the hypothesis testing results (figure 2).

Table1. Correlation Martrix

\begin{tabular}{|c|c|c|c|c|c|c|c|c|}
\hline & Mean & S.D. & ICR & Attitude & PEOU & PICM & PU & Usability \\
\hline Attitude & 5.20 & 1.00 & 0.86 & 0.81 & & & & \\
\hline PEOU & 6.30 & 1.34 & 0.74 & 0.30 & 0.81 & & & \\
\hline PICM & 5.74 & 0.97 & 0.88 & 0.36 & 0.61 & 0.76 & & \\
\hline PU & 5.91 & 1.06 & 0.87 & 0.41 & 0.40 & 0.44 & 0.83 & \\
\hline Usability & 5.87 & 0.86 & 0.92 & 0.41 & 0.52 & 0.64 & 0.68 & 0.89 \\
\hline AVE & & & & 0.67 & 0.65 & 0.58 & 0.69 & 0.79 \\
\hline
\end{tabular}

Note: Diagonal elements are the square root of the average variance extracted (AVE). Means and standard deviations are calculated based upon seven-point likert scales. 


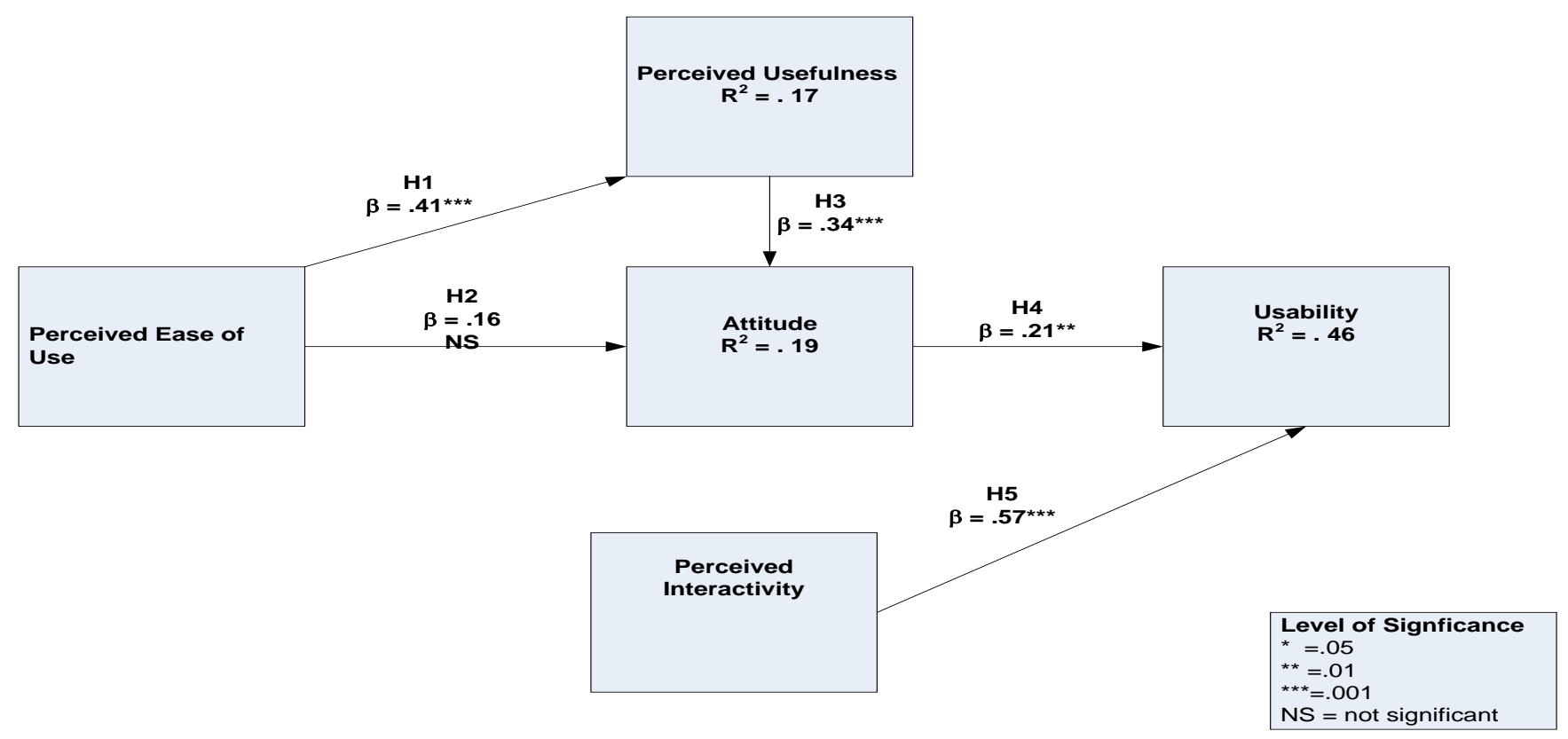

Figure 2

In general, the model is supported by the data. The following will give an overview of each hypothesis.

\section{Hypothesis 1}

Consistent with the TAM model, perceived ease of use is found to significantly impact perceived usefulness, where $\beta=.41, \mathrm{p}<.001, \mathrm{R}^{2}=.17$. This finding suggests that users in a Web 2.0 environment are similar to those in other computing environments.

\section{Hypothesis 2}

Contrary to the TAM model, perceived ease of use is found not to significantly impact attitude, where $\beta=$ $.16, \mathrm{p}<.01, \mathrm{R}^{2}=.19$. This finding suggests that a user's attitude in a Web 2.0 environment is not significantly impacted by a Web 2.0 tool that is perceived to be easy to use.

\section{Hypothesis 3}

Perceived usefulness, consistent with the TAM model, significantly impacts attitude, where $\beta=.34$, $\mathrm{p}<.001, \mathrm{R}^{2}=.19$. This finding suggests that users are concerned with what the Web 2.0 tool can possibly do for them with regard to social networking, gaming, or other activities.

\section{Hypothesis 4}

The attitude of the Web 2.0 user is found to significantly impact the usability of the website, where $\beta=.57, \mathrm{p}<.001, \mathrm{R}^{2}=.46$. This is similar to TAM in the sense that behavior can be impacted by attitude. The results suggest that those individuals with positive attitudes toward the Web 2.0 tool also perceive the usability of the tool to be adequate.

\section{Hypothesis 5}

Perceived interactivity is found to have a significant impact on usability, where $\beta=.57 \mathrm{p}<.001, \mathrm{R}^{2}=.46$. This finding suggests that the degree to which a user can interact with another user is most appealing to them, as opposed to what other mechanisms make the Web 2.0 tool functionality easier to use.

\section{Control variables}

Although controls for education level, income, and ethnicity were also collected, the gender variable was the only variable with a substantial amount of variance present. Gender was included in the model and was found to be a mildly significant predictor of usability where $\beta=.-13, \quad \mathrm{p}<.10, \mathrm{R}^{2}=.46$. 
Surprisingly, the gender variable had a negative impact on usability

Overall, the findings suggest that usability for social networking site users is primarily based upon interactions with others on the site, as well as other features that the site might be used for (i.e. gaming). Interactivity with other individuals, as opposed to the degree of functionality present in the Web 2.0 tool (given this data set), is a much better predictor of usability than one of the TAM variables (perceived ease of use). Arguably, perceived interactivity might plausibly be just as good of a predictor of website usability as the other TAM variable (perceived usefulness).

\section{DISCUSSION/CONCLUSION}

\section{Limitations}

This study is limited in a number of ways. The first is that the sample size is quite small ( 84 respondents). Also, the respondent group is homogeneous in multiple categories such as race (the sample is primarily African American) and age (the sample included mainly young people aged 18 to 24 years old). Furthermore, since a single survey instrument is used at a single point in time, the results may be subject to common methods bias and ambiguity in causal direction. Nevertheless, the study does suggest that there are other factors (besides TAM-related variables) that significantly impact website usability, specifically in a Web 2.0 context.

\section{Research implications}

This study examines website usability by incorporating perceived interactivity from the marketing literature to gain a greater understanding of technology acceptance. Future research should concentrate on examining other variablesspecifically those outside of mainstream IS literature - to gain a greater understanding of why human actors decide and continue to use Web 2.0 tools. Furthermore, this study incorporates the use of a demographic group (i.e. African American college students) that is not usually incorporated in many IS studies.

\section{Managerial implications}

Designers of Web 2.0 tools should continue to examine ways to improve how individual users can interact with one another. Regardless of how easy the website is to navigate (perceived ease of use), the results of this research suggest that users care more about perceptions of how they can interact with one another.

In conclusion, and in response to the continuing growth in use of social networking sites, this research proposes a conceptual model as a first step in seeking to understand social network use and possible determinants of use.

\section{REFERENCES}

[1] Agarwal, R., and Venkatesh, V., Assessing a firm's Web presence: A heuristic evaluation procedure for the measurement of usability, Information Systems Research 13 (2002), pp. 168.

Ajzen, I., Theory of planned behavior, Organizational Behavior and Human Decision Processes 50 (1991), pp. 179 211.

[3] Ajzen, I., Fishbein, M., Understanding attitudes and predicting social behavior, ed, Prentice Hall, Englewood Cliffs, NJ, 1980.

[4] Chin, W.W., The Partial Least Square Approach ot Structural Equation Modeling, in Modern Methods for Business Research, G.A. Marcoulides ed., Lawrence Erlbaum, Mahwah, NJ, 1998, pp. pg 295 - 336.

[5] Corbett, P., Facebook Demographics and Statistics Report, istrategy labs, 2009.

[6] ---, Facebook Demographics and Statistics Report, istrategy labs, 2010.

[7] Crawley-Boevey, S., Social network sites now checked more than personal email, in Brand Republic News Releases, 2009.

[8] Davis, F.D., Bagozzi, R.P., Warshaw, P.R., User acceptance of computer technology, Management Science 35 (1989), pp. 982 1003.

[9] Fishbein, M., Ajzen, I., Belief, Attitude, Intention and Behavior: An Introduction to Theory and Research, ed, Addison-wesley, Reading, MA, 1975.

[10] Fornell, ,C. Larcker, D., Evaluating Structural Equation Models with Unobservable Variables and Measurement Error, Journal of Marketing Research 18 (1981), pp. pp 39-50.

[11] Gibbs, C., Facebook triples wireless subscriber base, in RCR Wireless News, 2008.

[12] Grunig, J.E., Grunig, L. A. , Toward a Theory of Public Relations Behavior of Organizations: Review of a Program of Research, in Public Relations Research Annual, J.E.G.a.L.A. Grunig ed., Lawrence 
Erlbaum Associates, Hillsdale, NJ, 1989, pp. $27-63$.

[13] Hansen, T., Jensen J.M., Solgaard, H.S., Predicting Online Grocery buying Intention: A Comparison of The Theory of Reasoned Action and The Theory of Planned Behavior, International Journal of Information Management 24 (2004), pp. 530-550.

[14] Hempel, J., How Facebook is taking over our lives, in Fortune, 2009, pp. 49 - 56.

[15] Houghton, J., Face it, that book's productive, in Sunday Age, 2nd ed, Melbourne, 2008.

[16] Katz, M.L., Shapiro, C., Network externalities, competition and compatibility, American Economic Review (1985), pp. 424 - 440.

[17] Lankton, N., McKnight, D, H., Do People Trust Faccebook as a Technology or as a "Person"? Distinguishing Technology Trust from Interpersonal Trust, in Fourteenth Americas Conferrence on Information Systems, Toronto, ON, 2008.

[18] Newhagen, J.E., Corders, J.W., Levy, M.R. , Nightly@nbc.com: Audience Scope and the Perception of Interactivity in Viewer Mail on the Internet, Journal of communication 45 (1995), pp. 164 - 175

[19] Oliver, R.L., Bearden, W.O., Crossover Effects in the Theory of Reasoned Action: A Moderating Influence Attempt The Journal of Consumer Research 12 (1985), pp. 324 340.

[20] Rafaeli, S., Interactivity: From New Media to Communication, in Advancing Communication Science: Merging Mass and Interpersonal Processes, J.M.W. R.P. Hawkins, and S. Pingree ed., Sage Publications, . Newbury Park, CA, 1988, pp. $110-134$
[21] Sheppard, B.H., Hartwick, J., \& Warshaw, P. R. , The theory of reasoned action: A meta-analysis of past research with recommendations for modifications and future research, Journal of Consumer Research 15 (1988), pp. 325 - 343.

[22] Song, J.H., and Zinkhan, G.M., Determinants of Perceived Web Site Interactivity, Journal of Marketing 72 (2008), pp. 99.

[23] Steuer, J., Defining Virtual Reality: Dimensions Determining Telepresence, Journal of Communication 42 (1992), pp. 73 $-93$.

[24] Venkatesh, V., Davis, F.D, A Model of the Antecedents of Perceived Ease of Use: Development and Test, Decision Sciences 27 (1996), pp. 451-481.

[25] Venkatesh, V., and Ramesh, V., Web and Wireless Site Usability: Understanding Differences and Modeling Use, MIS Quarterly 30 (2006), pp. 181.

[26] Venkatesh, V., Speier, C. and Morris, M.G. , User Acceptance Enablers in Individual decision Making About Technology: Toward An Integrated Model, Decision Sciences 33 (2002), pp. 297-316.

[27] Venkatesh V.a.S., C. , A Theoretical Extension of the Technology Acceptance Model: Four Longitudinal Field Studies. , Management Science 46 (2000), pp. 186 204.

[28] Yu, T., Wu, G., Determinants of Internet Shopping Behavior: An Application of Reasoned Behaviour Theory, International Journal of Management 24 (2007), pp. 744762. 